\title{
Serum antibodies to West Nile virus in naturally exposed and vaccinated horses
}

\begin{abstract}
Correspondence
Louis A. Magnarelli

louis.magnarelli@po.state.ct.us
\end{abstract}

Received 27 December 2007

Accepted 22 May 2008

\author{
Louis A. Magnarelli, ${ }^{1}$ Sandra L. Bushmich, ${ }^{2}$ John F. Anderson, ${ }^{1}$ \\ Michel Ledizet ${ }^{3}$ and Raymond A. Koski ${ }^{3}$
}

\author{
${ }^{1}$ Connecticut Agricultural Experiment Station, New Haven, CT 06504, USA \\ ${ }^{2}$ Department of Pathobiology and Veterinary Science, University of Connecticut, Storrs, CT 06269, \\ USA \\ ${ }^{3} \mathrm{~L}^{2}$ Diagnostics, 300 George Street, New Haven, CT 06511, USA
}

\begin{abstract}
A polyvalent ELISA and plaque reduction neutralization tests (PRNTs) were used to measure serum antibodies to West Nile virus (WNV) in horses naturally exposed to or vaccinated against this flavivirus in Connecticut and New York State, USA. Relying on a PRNT as a 'gold standard', the main objective was to validate a modified ELISA containing a recombinant WNV envelope protein antigen. It was also important to assess specificity by testing sera from horses that had other, undiagnosed illnesses. Sera for the latter study were obtained from 43 privately owned horses during 1995-1996. Analyses by an ELISA and a PRNT confirmed the presence of WNV antibodies in 21 ( $91 \%$ ) of 23 sera from naturally exposed horses and in $85 \%$ of the 20 vaccinated subjects; overall results for both study groups were highly concordant $(91 \%$ agreement). Humoral responses of naturally exposed and immunized horses were similar. Both serological tests were useful in confirming past infections with WNV, but there was no evidence that horses with undiagnosed illnesses were exposed to WNV prior to a 1999 outbreak in Connecticut, USA.
\end{abstract}

\section{INTRODUCTION}

West Nile virus (WNV), which is widely distributed in Africa, the middle East and Europe, was first reported in North America in 1999, following the diagnosis of human infections and reports of fatalities in New York City, USA (Anderson et al., 1999; Lanciotti et al., 1999). Like other flaviviruses (flaviviridae), WNV is transmitted by mosquitoes and can infect a wide range of vertebrate hosts, including horses (Ward et al., 2004). During the period 1999-2003, more than 200 isolations of WNV were made from 17 mosquito species in 6 genera in Connecticut, USA (Andreadis et al., 2004). The broad feeding habits of key mosquito species include mammals as well as birds (Magnarelli, 1977; Molaei \& Andreadis, 2006) and, along with host competence, allow for rapid amplification and spread of select mosquito-borne viruses in nature. Bird migration, dispersal of non-migrating birds (e.g. the house sparrow, Passer domesticus), and the movement of mosquitoes contributed to the rapid spread of the virus from north-eastern USA to western and southern sections

Abbreviations: CAES, Connecticut Agricultural Experiment Station; CDC, Centers for Disease Control and Prevention; CVMDL, Connecticut Veterinary Medical Diagnostic Laboratory; IFA, indirect fluorescent antibody; PRNT, plaque reduction neutralization test; UCONN, University of Connecticut; WNV, West Nile virus. of the country, Canada and Mexico (Rappole \& Hubalek, 2003; Rappole et al., 2006). Thousands of human and horse infections have been reported (CDC, 2002).

Horses can be fed upon by infected Culex species and other key vectors of WNV in sheltered areas as well as in pastures and, if not vaccinated, may develop severe WNV meningoencephalomyelitis (Davidson et al., 2005). Laboratory diagnosis and ecological studies rely on detecting serum antibodies by an ELISA or neutralizing antibodies by a plaque reduction neutralization test (PRNT).

WNV is endemic in numerous regions of Europe and is known to re-emerge in some areas (Hubalek \& Halouzka, 1999). However, in the Tuscany region of Italy there was no evidence of virus activity prior to a 1998 outbreak (Autorino et al., 2002). Moreover, little is known about humoral responses in horses challenged by an experimental recombinant $\mathrm{WNV}$ envelope (E) protein vaccine (Ledizet et al., 2005), compared to those induced by a killed virus vaccine or by natural exposure to WNV.

The main objectives of the present study were to validate a modified polyvalent ELISA with a recombinant WNV E protein incorporated, to measure total serum antibodies in naturally exposed and vaccinated horses, and to compare ELISA results with those of two PRNT methods being used 
in different laboratories. It was also important to assess the specificity of serological tests.

\section{METHODS}

Sources of horse sera. There were three main study groups: subjects naturally exposed to WNV (group A) and found to be carrying antibodies to this pathogen; horses vaccinated against WNV (group B); and a panel of sera obtained from ill horses in Connecticut and New York State, USA, during the period 1995-1996, prior to the USA WNV outbreak (group C). Twenty-three samples in group A were selected from archived collections in the Department of Pathobiology and Veterinary Science at the University of Connecticut (UCONN). Of these, 19 were available for independent, comparative virus neutralization tests in different laboratories. The blood samples were collected between 2000 and 2003 from Connecticut and New York horses with clinical WNV disease; sera were known to contain antibodies to $\mathrm{WNV}$, as determined by serological testing performed at the Connecticut Veterinary Medical Diagnostic Laboratory (CVMDL) at UCONN. These sera were included in analyses to compare immunoassay methods.

Group B sera, also taken from UCONN collections, represented 20 horses immunized against WNV. These sera were included in analyses to compare antibody titres in naturally exposed and vaccinated horses. There were two subgroups of 10 horses each, where subjects were immunized following manufacturers' directions with a licensed killed WNV vaccine (Innovator) produced by Fort Dodge Animal Health and boosted the following year with either the Fort Dodge vaccine or an experimental recombinant WNV E protein subunit vaccine (Ledizet et al., 2005) produced by $\mathrm{L}^{2}$ Diagnostics. As reported by these authors, the horses selected for immunization had no prior histories of WNV infection or vaccination. Sera obtained before immunization were negative for antibodies to WNV, as determined by an ELISA or microsphere immunoassay. Each horse received two identical injections of the Fort Dodge vaccine 20 to 28 days apart in 2003. Serum samples tested in the present study were obtained approximately 2 months after a single booster injection in 2004 . Antibodies elicited by the vaccines were detectable in the sera by an ELISA and a PRNT (Ledizet et al., 2005).

The third group (C) consisted of serum samples representing 43 privately owned, ill horses from south-western Connecticut (27 serum samples) and the lower Hudson River region of New York State (16 serum samples). Sera were randomly selected for the present study from a larger panel of archived specimens, tested before for antibodies to Borrelia burgdorferi (Magnarelli \& Fikrig, 2005) and Anaplasma phagocytophilum (formerly Ehrlichia equi) (Magnarelli et al., 2000), and stored at $-60{ }^{\circ} \mathrm{C}$ at the Connecticut Agricultural Experiment Station (CAES). All horses in group C lived within $30 \mathrm{~km}$ of a site in Stamford, Connecticut, where WNV was first cultured from mosquitoes in North America during 1999 (Anderson et al., 1999). These sera were included in specificity analyses to determine if antibodies to tick-borne pathogens cross-react in an ELISA with WNV antigen. Details on clinical manifestations and passive surveillance programs for tick-borne infections in horses have been published (Magnarelli et al., 1997, 2000; Magnarelli \& Fikrig, 2005).

An additional 37 sera, from healthy horses not exposed to or vaccinated against $\mathrm{WNV}$, served as negative controls. Of these, 28 sera were obtained from equines during 1985 in Kent, Connecticut, a rural area of Litchfield County in the north-western part of the state. Vaccines for WNV immunization of equines were unavailable prior to 2001. The nine other negative control sera were received from the CVMDL. The positive control serum was from a horse immunized against WNV with the $\mathrm{L}^{2}$ vaccine at $\mathrm{UCONN}$ and contained high concentrations of antibodies ( $>1: 40960)$ to the vaccine antigen, as determined by an ELISA.

ELISA. A non-competitive, polyvalent ELISA described in previous studies (Magnarelli et al., 1984, 2000; Magnarelli \& Fikrig, 2005) and conducted at CAES was modified, as described here, to detect total antibodies to WNV. A recombinant truncated WNV E protein antigen (Ledizet et al., 2005; Wong et al., 2004) was mixed in a carbonate coating buffer solution $(\mathrm{pH} \mathrm{9.5)} \mathrm{and} \mathrm{affixed} \mathrm{to} \mathrm{flat-}$ bottomed, polystyrene plates (Nunc) at a concentration of $1 \mu \mathrm{g} \mathrm{ml} l^{-1}$ and a volume of $100 \mu \mathrm{l}$ per well. The plates were incubated overnight at $4{ }^{\circ} \mathrm{C}$. Unlike previous ELISA methods used at the CAES, preparations were not allowed to dry. The next day, plates were washed four times in PBS solution (PBSS, pH 7.2) containing $0.05 \%$ Tween 20 (Magnarelli et al., 1984). A preliminary blocking procedure with mammalian sera was not used as in previous studies conducted at the CAES because early trials with goat or bovine sera showed high background reactivity in test wells for negative controls. Horse sera were diluted in PBSS containing $0.05 \%$ Tween 20 to 1 in 160, 1 in 320 and 1 in 640, and samples were added at a $100 \mu \mathrm{l}$ volume to all test and control wells. Following incubation for $1 \mathrm{~h}$ at $37^{\circ} \mathrm{C}$, the plates were washed. Commercially produced (Kirkegaard and Perry Laboratories,), affinity-purified horseradish peroxidase-labelled goat anti-horse (heavy and light chains specific) immunoglobulins, which replaced the alkaline phosphatase conjugated antibodies used previously (Ledizet et al., 2005), were diluted to 1 in 8000 in PBSS and were subsequently added at a $100 \mu$ volume to each well. Conjugates that are heavy and light chain specific detect IgM and IgG antibodies (Magnarelli \& Anderson, 1989). Following incubation for $1 \mathrm{~h}$ at $37{ }^{\circ} \mathrm{C}$, the plates were washed four times with PBSS. The substrate, also purchased from Kirkegaard and Perry Laboratories, consisted of 2,2'-azino-di(3-ethylbenzthiazoline sulfonate) and was added at a $100 \mu \mathrm{l}$ volume to each well for colour production. A microplate spectrophotometer measured absorbance values ( absorbance values of preparations, including negative PBSS controls without antigen) at $414 \mathrm{~nm}$ after $30 \mathrm{~min}$ of incubation. Each plate contained controls for positive and negative sera, PBSS, conjugate and other reagents to either verify antigen reactivity or check for falsepositive results. Likewise, procedures were included to ensure assay standardization. Positive sera, with antibody titres of 1 in 640 in preliminary analyses, were retested to determine titration end points and to check reproducibility of results.

The general procedures used to determine cut-off values for positive results follow published protocols (Magnarelli et al., 1997, 2000). Twenty-eight sera, obtained in 1985 and representing clinically normal horses from Kent, Connecticut, were used to calculate cut-off values for positive ELISA results. The sera were diluted in PBSS to 1 in 160,1 in 320 and 1 in 640, and tested with the recombinant WNV E protein or without antigen (i.e. controls to assess non-specific, background reactivity). Net absorbance values, defined as the difference in absorbance between reactions with and without antigen, were determined for each serum dilution. Statistical analyses $($ mean $+3 \mathrm{SD})$ of net absorbance values were applied to define cutoff values. It was important to minimize or exclude normal background reactions caused by low concentrations of non-specific antibodies. Net absorbance positive cut-off values of $0.29,0.23$ and 0.17 were established for serum dilutions of 1 in 160, 1 in 320 and 1 in 640 , respectively. The 0.17 absorbance value was also used to identify positive reactions for serum dilutions of 1 in $>640$.

In vitro PRNT. PRNTs were relied on as primary diagnostic methods ('gold standards') to determine if horse serum antibodies inhibit WNV replication in cultured Vero cells. The materials and methods described by Wang et al. (2001) were used in the present study at the CAES. Briefly, $75 \mu \mathrm{l}$ virus (100 p.f.u. per well) were mixed with $75 \mu \mathrm{l}$ heat-inactivated, diluted horse serum in a 96-well microtitre plate and 
incubated at $37{ }^{\circ} \mathrm{C}$ for $1 \mathrm{~h}$. Serum-virus mixtures were then inoculated onto 3-day-old confluent monolayers of Vero cells in a six-well tissue culture plate and incubated at $37^{\circ} \mathrm{C}$ for $1 \mathrm{~h}$. The plates were mechanically shaken every $15 \mathrm{~min}$ and an agarose overlay was added. After the cells were incubated at $37{ }^{\circ} \mathrm{C}$ for 4 days, a second overlay containing $4 \%$ neutral red was added on day 5 . Virus plaques were counted $18 \mathrm{~h}$ later. Sera were diluted to 1 in 10, 1 in 20 and 1 in 40 initially, and, if positive at 1 in 40 , were subsequently titrated to 1 in 320 in replicated tests to assess the reproducibility of results. Reactions that resulted in an 80 or $95 \%$ reduction in viral plaque numbers were noted. Therefore, the recorded antibody titre was the highest serum dilution that neutralized at least 80 or $95 \%$ of the viral plaques.

A subset of 48 horse sera from subjects naturally exposed to WNV (group A, 19 serum samples), vaccinated for WNV (group B, 20 serum samples) or with no exposure to WNV (negative controls, 9 serum samples) also was analysed by a standard WNV neutralization assay using a microtitre plate method at the CVMDL following the National Veterinary Services Laboratory (Ames, IA, USA) 2004 protocol. Briefly, sera were heat inactivated at $56{ }^{\circ} \mathrm{C}$ for $30 \mathrm{~min}$ and subsequently diluted 1 in 5 in Dulbecco's modified Eagle's medium (DMEM) (Sigma-Aldrich) containing antibiotics and antimycotics. Twofold serial dilutions were made in duplicate rows of a 96-well plate. A serum control well was included for each sample. A total of $25 \mu \mathrm{lWNV}$, representing a $200 \mathrm{TCID}_{50}$ (50\% tissue culture infecting dose), was diluted in DMEM with antibiotics, antimycotics and $10 \%$ guinea pig complement, and then added to each well except the serum control wells. The $\mathrm{TCID}_{50}$ virus titre is defined as the reciprocal of the highest dilution of virus that infects $50 \%$ of the inoculated host cells in culture. Serum control wells received $25 \mu \mathrm{l}$ of the DMEM containing $10 \%$ guinea pig complement. After the virus was added, plates were incubated for $1 \mathrm{~h}$ at $37{ }^{\circ} \mathrm{C}$ with $5 \% \mathrm{CO}_{2}$. Vero 76 cells were prepared by growing in a $75 \mathrm{~cm}^{2}$ flask for 3 days until fully confluent. These cells were then split into $40 \mathrm{ml}$ of cell culture media. One hundred microlitres of the prepared Vero cells were then added to all wells. Plates were incubated for 4 to 5 days at $37{ }^{\circ} \mathrm{C}$ with $5 \%$ $\mathrm{CO}_{2}$, and the wells were examined for cytopathic effect using an inverted microscope. Positive and negative control sera were included in test trials. The end-point titre was the highest serum dilution in which no cytopathic effect was observed in both duplicate samples.

Indirect fluorescent antibody (IFA) staining. Analyses were conducted to further screen any horse sera obtained from ill subjects prior to the 1999 outbreak of WNV in New York or Connecticut and found to be positive by our modified ELISA and negative by PRNT for antibodies to this virus. Commercially prepared slides, containing fixed virus-infected Vero cells, were purchased (Panbio) and used following the manufacturer's directions to detect total antibodies. Slides contained viruses from the following groups: flavivirus (family Flaviviridae: WNV, St Louis encephalitis virus and Powassan virus); alphavirus (family Togaviridae: eastern equine encephalitis and western equine encephalitis viruses); and bunyavirus (family Bunyaviridae; La Crosse virus). The second antibody used was a fluorescein isothiocyanate-conjugated rabbit anti-horse immunoglobulin (Sigma-Aldrich) diluted to 1 in 64 with PBSS. Since background reactivity was evident at a serum dilution of 1 in 40 when a preimmune serum was tested, a serum dilution of 1 in 320 was used to judge reactivity of selected horse sera.

Specificity tests. Additional tests were conducted to assess specificity. To determine if there was cross-reactivity due to equine antibodies produced to common tick-associated bacterial infections, 43 horse sera (group C) were analysed by the modified ELISA for total antibodies to A. phagocytophilum and B. burgdorferi (Magnarelli et al., 2000, 2001, 2004; Magnarelli \& Fikrig, 2005). Humoral responses to these pathogens in horses can be robust with high concentrations of
IgM and IgG antibodies being produced. It was important to assess assay specificity because the presence of broadly reactive IgM antibodies can sometimes confuse ELISA and other serological test results, even though these antibodies are directed to antigens of unrelated pathogens. A recombinant p44 antigen of A. phagocytophi$l u m$, expressed and purified as a maltose-binding fusion protein, was used in a polyvalent ELISA, whereas in analyses for B. burgdorferi antibodies, whole-cell antigen (strain 2591) was incorporated in a polyvalent ELISA. Both bacterial agents are transmitted by Ixodes scapularis ticks in north-eastern United States and Ixodes ricinus ticks in Europe.

Statistical analyses. To assess concordance of assay results, significant differences in percentages of positive results were determined by using a $z$ test with Yate's correction (Sigmastat; SPSS). Values of $P<0.05$ were considered to be statistically significant.

\section{RESULTS AND DISCUSSION}

\section{ELISA and PRNT concordance}

Analyses by an ELISA and PRNT (at 95\% plaque reduction) confirmed the presence of serum antibodies to WNV in 21 (91\%) of 23 serum specimens representing natural infections in horses (group A). At an $80 \%$ plaque reduction rate, all 23 sera were positive. Similarly, $85 \%$ of the 20 vaccinated horses (group B) were positive in both tests (Table 1). Although the seropositivity value in the PRNT $(95 \%$ positive at the $95 \%$ plaque reduction rate) exceeded that of an ELISA ( $85 \%$ positive) for vaccinated subjects, the difference was not statistically significant $(z=0.53, P=0.60)$. Overall serological results for both of these study groups were highly concordant ( $91 \%$ agreement).

\section{Interlaboratory concordance of PRNT results}

To compare results obtained independently in different laboratories, virus neutralization analyses also were conducted at the CVMDL. All 20 vaccinated horses (group B) included in the test panel were positive ( $\geqslant 1$ in 10 titre), compared to the 19 positives identified by this method at the CAES. The CVMDL neutralization titre for the remaining serum sample, in reference to the discrepant result, was 1 in 25. Parallel tests performed on a subset of 19 horse sera representing natural exposure to WNV (group A) revealed $100 \%$ concordance in neutralization test results at the CVMDL and CAES. Moreover, all nine negative control sera were non-reactive in both laboratories.

\section{ELISA versus PRNT testing}

All three serological tests were useful in detecting antibodies to WNV in naturally exposed and vaccinated horses. It was particularly helpful to have PRNT results to interpret ELISA findings. Although laborious and time consuming, the PRNT yields more definitive results and is a reliable confirmatory method, while an ELISA is advantageous as a rapid pre-screening procedure in surveillance programs (Castillo-Olivares \& Wood, 2004). 
Table 1. Results of analyses for antibodies to WNV in horse sera from Connecticut and New York State by PRNT and a polyvalent ELISA containing recombinant envelope protein antigen

\begin{tabular}{|c|c|c|c|c|}
\hline \multirow[t]{2}{*}{ Study group } & \multicolumn{2}{|c|}{ PRNT $^{\star}$} & \multicolumn{2}{|c|}{ ELISA $^{\star}$} \\
\hline & Total sera tested & No. (percentage) positive & Total sera tested & No. (percentage) positive \\
\hline Natural infection (A) & 23 & $21(91)$ & 23 & $21(91)$ \\
\hline Vaccinated (B) & 20 & $19(95)$ & 20 & $17(85)$ \\
\hline Unknown history $(\mathrm{C}) \dagger$ & 34 & $0(0)$ & 43 & $4(9)$ \\
\hline Negative control & 9 & $0(0)$ & 9 & $0(0)$ \\
\hline
\end{tabular}

${ }^{\star}$ Positive by PRNT when at least $95 \%$ neutralization of p.f.u. was detected. Positive ELISA antibody titres were $\geqslant 1$ in 160 .

$\dagger$ Unknown history refers to blood samples drawn from ill horses in 1995-1996 prior to the 1999 outbreak of human and horse cases of West Nile encephalitis in north-eastern USA. All tests were performed on one serum sample per animal at the CAES.

However, many variations exist in ELISA methodologies to detect antibodies to WNV, and there is potential for falsepositive results when whole-cell viral antigens are used to detect IgM antibodies (Davidson et al., 2005). Our modified ELISA with recombinant WNV E protein antigens used with peroxidase-labelled goat anti-horse immunoglobulins yielded sensitive and reproducible results. The recombinant WNV E protein antigens were sufficiently reactive in the present study, and likewise have been used effectively by other investigators in a suspended microsphere immunoassay to detect $\mathrm{WNV}$ antibodies in human and equine sera (Wong et al., 2004; Balasuriya et al., 2006). Therefore, the use of recombinant viral antigens is an acceptable alternative to the use of whole-cell antigens.

\section{Naturally infected versus vaccinated horse sera}

Antibody titres, measured by our modified ELISA, for naturally infected (group A) and vaccinated (group B) horses were comparable. However, a wide range of titration end points was noted for both groups (Table 2), with a skew toward higher titres. In each case, more than $77 \%$ of the antibody titres were greater than 1 in 1280 . Geometric means of 2243 and 2004 were calculated for naturally infected and vaccinated horses, respectively. For the latter group, the geometric mean for horses boosted with the recombinant E protein (3225) exceeded that calculated (1174) for the Fort Dodge vaccine, as determined by the ELISA containing recombinant $\mathrm{E}$ protein antigen.

Neutralizing antibody titres for naturally infected (group A) and vaccinated (group B) horses varied. At a $95 \%$ plaque reduction rate for group $\mathrm{A}$, horse sera diluted from 1 in 10 to $\geqslant 1$ in 320 decreased viral plaque numbers (Tables 1 and 2). At $80 \%$ neutralization of p.f.u., all 23 sera in group A were considered positive with a PRNT titre of $\geqslant 1$ in 320 being most frequently recorded (17 samples); the remaining sera had neutralizing antibodies at concentrations of 1 in 40 ( 1 sample), 1 in 80 (4 samples) and 1 in 160 ( 1 sample). The frequency distribution for neutralizing antibody titres in group B vaccinated subjects paralleled those recorded for natural infections (Table 2). All 10 horses that were boosted with the Fort Dodge vaccine developed neutralizing antibodies that decreased viral plaque numbers by $95 \%$; serum dilutions ranged from 1 in 10 to $\geqslant 1$ in 320. Similarly, 9 out of 10 other horses boosted with the experimental recombinant subunit vaccine had concentrations of neutralizing antibodies in the same range. Serum from the remaining vaccinated horse was negative by ELISA and the PRNT at both the 95 and $80 \%$ plaque reduction rates.

Table 2. Frequency distributions of serum antibody titres for horse sera positive by a polyvalent ELISA or in PRNTs

\begin{tabular}{|c|c|c|c|c|}
\hline \multirow{3}{*}{$\begin{array}{l}\text { Reciprocal } \\
\text { antibody titres }\end{array}$} & \multicolumn{4}{|c|}{ No. of sera with positive antibody titres ${ }^{\star}$} \\
\hline & \multicolumn{2}{|c|}{ ELISA } & \multicolumn{2}{|c|}{ PRNT } \\
\hline & $\begin{array}{l}\text { Natural } \\
\text { infection }\end{array}$ & Vaccinated & $\begin{array}{l}\text { Natural } \\
\text { infection }\end{array}$ & Vaccinated \\
\hline 10 & $\mathrm{NA}$ & $\mathrm{NA}$ & 1 & 2 \\
\hline 20 & $\mathrm{NA}$ & NA & 5 & 1 \\
\hline 40 & $\mathrm{NA}$ & $\mathrm{NA}$ & 1 & 2 \\
\hline 80 & $\mathrm{NA}$ & NA & 2 & 4 \\
\hline 160 & 0 & 1 & 9 & 3 \\
\hline 320 & 1 & 1 & 3 & 7 \\
\hline 640 & 1 & 2 & $\mathrm{NA}$ & $\mathrm{NA}$ \\
\hline 1280 & 4 & 4 & $\mathrm{NA}$ & $\mathrm{NA}$ \\
\hline 2560 & 10 & 3 & $\mathrm{NA}$ & $\mathrm{NA}$ \\
\hline 5120 & 5 & 3 & $\mathrm{NA}$ & $\mathrm{NA}$ \\
\hline 10240 & 0 & 3 & NA & NA \\
\hline $\begin{array}{l}\text { Total positive } \\
\text { horse sera }\end{array}$ & 21 & 17 & 21 & 19 \\
\hline
\end{tabular}

NA, Not applicable.

${ }^{\star}$ Positive antibody titres by ELISA were $\geqslant 1$ in 160 . Seropositive PRNT indicates $95 \%$ neutralization of p.f.u. at all specified serum dilutions but this was not tested beyond 1 in 320. All tests were performed at the CAES. 


\section{Vaccine-induced humoral responses}

Humoral responses of naturally exposed horses (group A) were similar to those of vaccinated subjects (group B). Seropositivity rates and antibody titres recorded for the two groups were similar, as were the neutralizing titres. When the two vaccinated groups were compared, the virus neutralization titres were likewise comparable. Relatively low ELISA and PRNT titres recorded after the use of a killed virus vaccine in other mammals (Tesh et al., 2002; Kutzler et al., 2004) may, along with cellular immune activity, provide protection against WNV. One vaccinated horse in the present study, however, did not have detectable antibodies to $\mathrm{WNV}$ recombinant $\mathrm{E}$ protein antigen. Nonetheless, performance of the two vaccines was considered comparable; the difference in detectable responses $(100 \%$ vs $90 \%)$ can be attributed to variable immune responses in a diverse population. In other studies, antibodies were not detected in some horses immunized with the killed WNV vaccine (Davidson et al., 2005). Furthermore, in horses challenged with inactivated eastern equine encephalitis virus, antibodies did not persist in some subjects beyond 2 months after vaccination (Barber et al., 1978). Viraemia in horses can be relatively low and of short duration (Castillo-Olivares \& Wood, 2004), particularly in horses infected by mosquito bites (Bunning et al., 2002). Moreover, IgM antibodies may rise slowly during early infection, remain detectable for limited periods of time ( $<3$ months) following natural infection and, in some horses, may not even be produced in measurable amounts following WNV vaccination (CastilloOlivares \& Wood, 2004). It should also be noted that in tests of human sera from persons diagnosed with La Crosse virus infections (Calisher et al., 1986), IgM antibody produced early in the illness does not always show neutralizing activity. Therefore, careful consideration should be given to the time at which blood samples are taken from subjects relative to the onset of clinical signs of illness, and to the selection of sensitive antibody tests to minimize false-negative results. Furthermore, in view of the variable immune responses among horses, due to age, breed and other factors (Davidson et al., 2005), and the abundance of infected mosquitoes that can occur in certain locations, vaccination for WNV may be needed every 6 months for some horses (Davidson et al., 2005). These authors reported that vaccine-induced antibody responses decreased with the age of the horses. Therefore, it is an acceptable option to test horse sera post-vaccination to determine if antibodies have been produced.

\section{Assay specificity}

In specificity studies, three $(13 \%)$ of the horses naturally exposed to WNV (group A) contained antibodies to this pathogen and also had antibodies to A. phagocytophilum or B. burgdorferi. Two of the forty-three sera representing horses with undiagnosed illnesses prior to 1999 (group C) and tested at the CAES contained relatively high concentrations of antibodies to all three pathogens (Table 3$)$. Three $(11 \%)$ of the twenty-eight sera (group C) containing antibodies to one or more bacterial pathogens had antibodies to WNV. Single reactions to separate antigens ( $n=15$ sera, $35 \%)$ nearly equalled multiple reactions to different disease organisms $(n=14$ sera, $33 \%)$. Based on these results, there was no convincing evidence of cross-reactivity in our ELISA for WNV antibodies being caused by high concentrations of antibodies to A. phagocytophilum or B. burgdorferi.

In analyses of 43 horse sera in group $\mathrm{C}$, obtained from ill animals prior to the 1999 WNV outbreak, 4 (9\%) specimens were positive by our modified ELISA but negative in the PRNT (Table 1). These horses resided in south-western Connecticut in the following towns: Bethany, Newtown (two horses) and Weston. In an ELISA, antibody titres ranged from 1 in 640 to 1 in 1280 .

Table 3. Comparison of serological test results for 43 horse sera from subjects with undiagnosed illnesses prior to 1999 (group C) that were tested for antibodies to WNV, A. phagocytophilum and/or B. burgdorferi by separate polyvalent ELISAs

\begin{tabular}{|lcccc|}
\hline Antigen group & No. positive & \multicolumn{3}{c|}{ Reciprocal antibody titre (range) } \\
\cline { 3 - 5 } & & WNV & AP & BB \\
\hline WNV & 1 & 1280 & - & - \\
WNV + AP & 0 & - & - & - \\
WNV + AP + BB & 2 & 1280 & $(640-5120)$ & $(2560-5120)$ \\
WNV + BB & 1 & 640 & - & 2560 \\
AP & 2 & - & $(160-10240)$ & - \\
AP + BB & 11 & - & - & $(640-40960)$ \\
BB & 12 & - & & $960)$ \\
Total no. $(\%)$ positive & $29(67 \%)$ & & & \\
\end{tabular}

${ }^{\star}$ Recombinant envelope E protein antigen was used in an ELISA for WNV antibodies, whereas recombinant protein 44 and whole-cell antigens of A. phagocytophilum (AP) and B. burgdorferi (BB), respectively, were incorporated separately in an ELISA. All tests were performed at the CAES. 
All nine sera from a negative control group were nonreactive by both assay methods (Table 1 ). Based on these preliminary results, we suspected that the four positive sera obtained prior to 1999 might have antibodies to other flaviviruses related to WNV, such as St Louis encephalitis virus or Powassan virus. The latter human pathogen occurs in north-eastern and western USA and Ontario, Canada (Gritsun et al., 2003), where Ixodes cookei, an important vector, and other hard-bodied ticks occur. Exposure to the 'deer tick virus', a subtype of Powassan virus, is also a possibility for subjects in this group (Ebel et al., 2000). In serological tests of human and horse sera for Flavivirus antibodies, cross-reactivity among closely related viruses in this serogroup is well documented (Castillo-Olivares \& Wood, 2004; Wong et al., 2004; Martin et al., 2000; Johnson et al., 2005), regardless of the antigens incorporated in the assays. The high degree of structural relatedness of $\mathrm{E}$ proteins among flaviviruses is an important factor that can lead to false positives when antibodies are present to such agents as Powassan, St Louis encephalitis, Japanese encephalitis or dengue viruses. However, there are no reports of the latter three viruses occurring naturally in Connecticut or Europe. Further, in more than 10 years of statewide surveillance, conducted at CAES for encephalitis viruses in Connecticut mosquitoes, St Louis encephalitis virus has never been isolated. Although travel histories for the four positive horses are unknown, it is not uncommon for these animals to be moved nationally or internationally. We recognize that horses that travel to midwestern or southern USA may be exposed to St Louis encephalitis virus there. PRNT assays, kindly conducted at the Arbovirus Laboratory, Wadsworth Center, New York State Department of Health (Albany, New York, USA) and following the methods of Lindsey et al. (1976), indicated antibody titres of $<1$ in 10 against St Louis encephalitis virus, WNV and Powassan virus. In addition, results of IFA staining methods revealed a pattern of uniform, diffuse cytoplasmic staining that was not specific to any particular family of viruses tested. Therefore, we conclude that reactivity of the four horse sera from ill subjects in our modified ELISA was probably due to binding of non-specific antibodies. Based on the results of our modified ELISA and the negative PRNT findings for the 4 sera reactive in this ELISA, we also conclude that none of the 43 (group C) horses tested in the present study had exposure to WNV prior to the 1999 outbreak in the north-eastern USA. Although it is unknown how WNV entered North America, there was a rapid emergence and spread of the virus over a large geographical region of the western hemisphere during and after that year. It is, therefore, important to monitor for the introduction of exotic viruses and other pathogens, in conjunction with surveillance and pathogen isolation programmes for mosquitoes, ticks and other haematophagous arthropods. Serological assays, such as the ELISA described in the present study, can be used as aids in laboratory diagnosis and ecological studies.

\section{ACKNOWLEDGEMENTS}

The authors are grateful to Tia Blevins and Bonnie Hamid of CAES for technical assistance, and thank Dr Laura D. Kramer and Alan P. Dupuis of the Arbovirus Laboratory, Wadsworth Center, New York State Department of Health, for conducting selected PRNT. We also acknowledge the assistance given by Dr Nathalie Bonafe of $\mathrm{L}^{2}$ Diagnostics in utilizing IFA staining methods to test for antibodies to encephalitis viruses. This research was funded, in part, by Hatch funds administered by the United States Department of Agriculture (USDA), a cooperative agreement (58-6615-1-218) from the USDA and a National Institutes of Health grant (R44 AI 49646).

\section{REFERENCES}

Anderson, J. F., Andreadis, T. G., Vossbrinck, C. R., Tirrell, S., Wakem, E. M., French, R. A., Garmendia, A. E. \& Kruiningen, H. J. (1999). Isolation of West Nile virus from mosquitoes, crows, and a Cooper's hawk in Connecticut. Science 286, 2331-2333.

Andreadis, T. G., Anderson, J. F., Vossbrinck, C. R. \& Main, A. J. (2004). Epidemiology of West Nile virus in Connecticut: a five year analysis of mosquito data 1999-2003. Vector Borne Zoonotic Dis 4, 360-378.

Autorino, G. L., Battisti, A., Deubel, V., Ferrari, G., Forletta, R., Giovannini, A., Lelli, R., Murri, S. \& Scicluna, M. A. (2002). West Nile virus epidemic in horses, Tuscany Region, Italy. Emerg Infect Dis $\mathbf{8}$, 1372-1378.

Balasuriya, U. B., Shi, P.-Y., Wong, S. J., Demarest, V. L., Gardner, I. A., Hullinger, P. J., Ferraro, G. L., Boone, J. D., De Cino, C. L. \& other authors (2006). Detection of antibodies to West Nile virus in equine sera using microsphere immunoassay. J Vet Diagn Invest 18, 392-395.

Barber, T. L., Walton, T. E. \& Lewis, K. J. (1978). Efficiency of trivalent inactivated encephalomyelitis virus vaccine in horses. Am J Vet Res 39, 621-625.

Bunning, M. L., Bowen, R. A., Cropp, C. B., Sullivan, K. G., Davis, B. S., Komar, N., Godsey, M. S., Baker, D., Hettler, D. L. \& other authors (2002). Experimental infection of horses with West Nile virus. Emerg Infect Dis 8, 380-386.

Calisher, C. H., Pretzman, S. I., Muth, D. F., Parsons, M. A. \& Peterson, E. D. (1986). Serodiagnosis of La Crosse virus infections in humans by detection of immunoglobulin M class antibodies. J Clin Microbiol 23, 667-671.

Castillo-Olivares, J. \& Wood, J. (2004). West Nile virus in horses. Vet Res 35, 467-483.

CDC (2002). West Nile virus activity - United States, November 2126, 2002. MMWR Morb Mortal Wkly Rep 51, 1072-1073.

Davidson, A. H., Traub-Dargatz, J. L., Rodeheaver, R. M., Ostlund, E. N., Pedersen, D. D., Moorhead, R. G., Stricklin, J. B., Dewell, R. D., Roach, S. D. \& other authors (2005). Immunologic responses to West Nile virus in vaccinated and clinically affected horses. J Am Vet Med Assoc 226, 240-245.

Ebel, G. D., Campbell, E. N., Goethert, H. K., Spielman, A. \& Telford, S. R., III (2000). Enzootic transmission of deer tick virus in New England and Wisconsin sites. Am J Trop Med Hyg 63, 36-42.

Gritsun, T. S., Nuttall, P. A. \& Gould, E. A. (2003). Tick-borne flaviviruses. In The Flaviviruses: Detection, Diagnosis, and Vaccine Development, vol. 61, pp. 317-371. Edited by T. J. Chambers \& T. P. Monath. San Diego, CA: Elsevier.

Hubalek, Z. \& Halouzka, J. (1999). West Nile fever - a reemerging mosquito-borne viral disease in Europe. Emerg Infect Dis 5, 643-650. 
Johnson, A. J., Noga, A. J., Kosoy, O., Lanciotti, R. S., Johnson, A. A. \& Biggerstaff, B. J. (2005). Duplex microsphere-based immunoassay for detection of anti-West Nile virus and anti-St. Louis encephalitis virus immunoglobulin M antibodies. Clin Diagn Lab Immunol 12, 566-574.

Kutzler, M. A., Baker, R. J. \& Mattson, D. E. (2004). Humoral response to West Nile virus vaccination in alpacas and llamas. J Am Vet Med Assoc 225, 414-416.

Lanciotti, R. S., Roehrig, J. T., Deubel, V., Smith, J., Parker, M., Steele, K., Crise, B., Volpe, K. E., Crabtree, M. B. \& other authors (1999). Origin of the West Nile virus responsible for an outbreak of encephalitis in the northeastern United States. Science 286, 2333-2337.

Ledizet, M., Kar, K., Foellmer, H. G., Wang, T., Bushmich, S. L., Anderson, J. F., Fikrig, E. \& Koski, R. A. (2005). A recombinant envelope protein vaccine against West Nile virus. Vaccine 23, 3915-3924.

Lindsey, H. S., Calisher, C. H. \& Mathews, J. H. (1976). Serum dilution neutralization test for California group virus identification and serology. J Clin Microbiol 4, 503-510.

Magnarelli, L. A. (1977). Host feeding patterns of Connecticut mosquitoes (Diptera: Culicidae). Am J Trop Med Hyg 26, 547-552.

Magnarelli, L. A. \& Anderson, J. F. (1989). Class-specific and polyvalent enzyme-linked immunosorbent assays for detection of antibodies to Borrelia burgdorferi in equids. J Am Vet Med Assoc 195, $1365-1368$.

Magnarelli, L. A. \& Fikrig, E. (2005). Detection of antibodies to Borrelia burgdorferi in naturally infected horses in the USA by enzyme-linked immunosorbent assay using whole cell and recombinant antigens. Res Vet Sci 79, 99-103.

Magnarelli, L. A., Meegan, J. M., Anderson, J. F. \& Chapell, W. A. (1984). Comparison of an indirect fluorescent-antibody test with an enzyme-linked immunosorbent assay for serological studies of Lyme disease. J Clin Microbiol 20, 181-184.

Magnarelli, L. A., Flavell, R. A., Padula, S. J., Anderson, J. F. \& Fikrig, E. (1997). Serologic diagnosis of canine and equine borreliosis: use of recombinant antigens in enzyme-linked immunosorbent assays. J Clin Microbiol 35, 169-173.

Magnarelli, L. A., IJdo, J. W., Van Andel, A. E., Wu, C., Padula, S. J. \&

Fikrig, E. (2000). Serologic confirmation of Ehrlichia equi and Borrelia burgdorferi infections in horses from the northeastern United States. $J$ Am Vet Med Assoc 217, 1045-1050.

Magnarelli, L. A., IJdo, J. W., Van Andel, A. E., Wu, C. \& Fikrig, E. (2001). Evaluation of a polyvalent enzyme-linked immunosorbent assay incorporating a recombinant p44 antigen for diagnosis of granulocytic ehrlichiosis in dogs and horses. Am J Vet Res 62, 29-32.

Magnarelli, L. A., Bushmich, S. L., Sherman, B. A. \& Fikrig, E. (2004). A comparison of serologic tests for the detection of serum antibodies to whole-cell and recombinant Borrelia burgdorferi antigens in cattle. Can Vet J 45, 667-673.

Martin, D. A., Muth, D. A., Brown, T., Johnson, A. J., Karabatsos, N. \& Roehrig, J. T. (2000). Standardization of immunoglobulin M capture enzyme-linked immunosorbent assays for routine diagnosis of arboviral infections. J Clin Microbiol 38, 1823-1826.

Molaei, G. \& Andreadis, T. G. (2006). Identification of avian and mammalian-derived bloodmeals in Aedes vexans and Culiseta melanura (Diptera; Culicidae) and its implication for West Nile virus transmission in Connecticut, U.S.A. J Med Entomol 43, 1088-1093.

Rappole, J. H. \& Hubalek, Z. (2003). Migrating birds and West Nile virus. J Appl Microbiol 94, 47S-58S.

Rappole, J. H., Compton, B. W., Leimgruber, P., Robertson, J., King, D. I. \& Renner, S. C. (2006). Modeling movement of West Nile virus in the western hemisphere. Vector Borne Zoonotic Dis 6, 128-139.

Tesh, R. B., Arroyo, J., Travassos da Rosa, A. P., Guzman, H., Xiao, S.-Y. \& Monath, T. P. (2002). Efficacy of killed virus vaccine, live attenuated chimeric virus vaccine, and passive immunization for prevention of West Nile virus encephalitis in hamster model. Emerg Infect Dis 8, 1392-1397.

Wang, T., Anderson, J. F., Magnarelli, L. A., Wong, S. J., Koski, R. A. \& Fikrig, E. (2001). Immunization of mice against West Nile virus with recombinant envelope protein. J Immunol 167, 5273-5277.

Ward, M. P., Levy, M., Thacker, H. L., Ash, M., Norman, S. K. L., Moore, G. E. \& Webb, P. W. (2004). Investigation of an outbreak of encephalomyelitis caused by West Nile virus in 136 horses. J Am Vet Med Assoc 225, 84-88.

Wong, S. J., Demarest, V. L., Boyle, R. H., Wang, T., Ledizet, M., Kar, K., Klamer, L. D., Fikrig, E. \& Koski, R. A. (2004). Detection of human anti-Flavivirus antibodies with a West Nile virus recombinant antigen microsphere immunoassay. J Clin Microbiol 42, 65-72. 